\title{
RETRACTION
}

The following article was withdrawn by the Editorial Board of ISIJ International on October 31, 2014, because it was submitted without consent of the coauthors.

\section{Retraction: Gaseous Pre-reduction for the Magnetic Beneficiation of Ferruginous Low-grade Mn Ore}

Yubo GAO, ${ }^{1)}$ Hang Goo $\mathrm{KIM}^{1)}$ Hong Yong SOHN ${ }^{1)}$ and Chan Wook $\mathrm{KIM}^{2)}$

1) Department of Metallurgical Engineering, University of Utah, Salt Lake City, Utah, 84112 USA.

2) Research Institute of Industrial Science and Technology, Pohang, Korea.

This article was published in ISIJ Int., 52 (2012), No. 5, 759-763. 